\title{
Argumentation for Impact of Indoor Environmental Quality on Users' Performance: Online Self-assessment Questionnaire.
}

\author{
Nada Atef Mohamed El Tohamy ${ }^{1}$ \\ Hanan Mostafa Kamal Sabry ${ }^{1}$ \\ Ahmed Atef El Dessoqy Faggal ${ }^{1}$ \\ ${ }^{1}$ Department of architecture, Faculty of engineering, Ain Shams university.
}

\begin{abstract}
When constructing a building, it is easy to forget that the success or failure of any project may rest on its indoor environmental quality (IEQ). Healthy and comfortable employees are often more productive especially considering that people spend $90 \%$ of their time indoors (LEED V4, 2014).

The aim of this paper is to find out Indoor environmental quality factors that office building users are concerned with the most and to figure out which factors are having the greatest effect on their performance and satisfaction. The data analyzed and discussed in this paper was collected using an online self-assessment questionnaire. Self-assessment questionnaire is considered a method of applying post occupancy evaluation for a building, reliability of this approach is being relevant to everyday office work and can deal with descriptive, qualitative and subjective characteristics. Responses of 118 office occupants in Egypt showed that 32.7\% voted for thermal comfort as the indoor environmental quality factor having the highest effect over their work performance. When asked about sources of dissatisfaction in the office environment, Problems related to visual comfort earned $36.1 \%$ of the overall dissatisfaction sources, these problems were presented in the lack of having a window, window area is too small, insufficient daylighting, poor lighting levels, glare on computer screens, and lack of outdoor natural views within the workspace.
\end{abstract}

\section{Keywords}

Indoor environmental quality; Building user performance; Online self-assessment questionnaire 


\section{Introduction}

Recently, there is a growing interest in proving the impact of the building features especially indoor environmental quality- on the performance and health of the building users. Proving this link encourages designers and owners to adopt strategies of sustainable and green design. Decisions taken by interior designers has a vital role in assuring that most commercial and office interior constructed are offering better indoor environment conditions for their users, improving their health, performance, satisfaction and comfort (Freihoefer, et al., 2015). Common features of a green building are conserving natural resources, resulting in lower levels ofpollutants and emissions from building materials and finishes, better ventilation systems and lighting quality (Harris \& Moore, 2009). Many indoor environment factors can raise comfort levels, but it should be considered that while performance is not directly correlated to comfort levels, work engagement is (Feige , et al., 2013).

The environmental aspects of the building design, especially quality of the indoor environment, were proved to affect user's health and productivity in various research studies. A large set of health issues is due to poor indoor environments and Indoor exposure to air pollutants such as allergic and asthmatic reactions. Sick building syndrome ${ }^{1}$ (SBS) symptoms, building-related illness and Legionnaire's disease $^{2}$ are some of the well-known side effects of poor office environments. Harmful impact of poor IEQ conditions would appear in the form of absenteeism, illness, direct and indirect medical costs and performance deterioration before a serious incident. Moreover, exposure to indoor pollutants and inconvenient ventilation negatively affect work performance even before the user can identify any physical manifestation of illness (Harris \& Moore, 2009).

In most design projects, it is not easy to create a fascinating, environment friendly, sustainable and cost-effective work environment. Aiming to achieve ecological goals while being cost efficient is often resisted as this results in long planning phase and more project revisions, that's why major of investment decisions are made depending on financial basis keeping environmental and social aspects often marginalized (Feige, et al., 2013). However, considering the total cost of the building over its lifetime, construction and running costs are not comparable to business running costs and occupants' salaries. Adopting this concept would make it more logic to optimize occupants' workspace, ensure their performance and productivity are at highest levels and their absenteeism is minimized (McCartney \& Humphreys, 2002).

\footnotetext{
${ }^{1}$ Sick building syndrome (SBS): Acute health and discomfort symptoms experienced by building users and linked to time spent in a building, but no specific illness or cause can be identified.

${ }^{2}$ Legionnaire's disease: is a severe infection caused by Legionella species. Symptoms may include a high fever, chills, cough, muscle aches, headaches.
} 


\section{Objectives}

This paper is considered a part of a more comprehensive research aiming at evaluating indoor environmental quality in green office buildings especially those are LEED certified. The aim of this paper is to evaluate how office building users perceive the importance and the effect of IEQ factors on their performance by applying a method of post occupancy evaluation represented in the self-assessment questionnaire.

\section{Methodology}

This paper is composed of two parts: The first part includes a review of the literature about the importance of indoor environment quality factors and their effect on human performance in office environment, explaining different approaches used to evaluate indoor environmental quality. The second part represents practical application of evaluating Indoor environmental quality by implementing an online self-assessment questionnaire measuring the importance of each of these factors from the perspective of office occupants. This paper is concerned with explaining the questionnaire methodology and procedures in addition to analysis and discussion of the collected data.

\section{Indoor Environmental Quality (IEQ) Impact on Performance and Health}

Indoor air quality (IAQ), Thermal comfort, Visual comfort, and Acoustics were found to be the most affecting the overall indoor environment of all IEQ factors and consequently, the most affecting human's perception of satisfaction and comfort. Each of these four factors affects human performance and health:

\section{a. Indoor air quality (IAQ)}

Frequent exposure to poor indoor air quality was proved to cause a wide range of symptoms reported as following (Harris \& Moore, 2009):

- Chronic exposure to high concentrations of pollutants such as radon, asbestos and tobacco smoke can increase risk of serious respiratory diseases and cancers.

- Acute exposure to some pollutants can result in common infectious diseases including cold, influenza, and Legionnaire's disease.

- Common illness symptoms caused by poor IAQ and low ventilation rate are dry eyes, headache, cough, wheeze, temporary eye, nose or throat irritation, skin irritation, and mental fatigue which collectively are sick building syndrome (SBS) symptoms.

- Naturally ventilated and air-conditioned buildings comparison showed that air- conditioned buildings have a higher risk of getting an acute respiratory disease and more sick building syndrome (SBS) symptoms. 
- SBS symptoms are more likely to happen at ventilation rates below 10 $\mathrm{L} / \mathrm{s} /$ person $^{1}$ and every $5 \mathrm{~L} / \mathrm{s} /$ person increase in ventilation rate would decrease common SBS symptoms by $35 \%$.

However, improving IAQ conditions could positively affect health and performance as following:

- Improving air quality and increasing fresh air supply rate by $10 \mathrm{~L} / \mathrm{s} /$ person can improve average performance by $1-3 \%$ and can achieve up to $20 \%$ reduction in respiratory disease infections which counts for 37 million cases annually only in the United states (Harris \& Moore, 2009).

- Reducing $10 \%$ of the population percentage dissatisfied with air quality corresponds to about a $1.1 \%$ increase in the performance of office work (Feige , et al., 2013).

- Doubling ventilation rate between 3-30 L/s/person can reduce illness by $10 \%$, improve work performance by around $1.5-2.1 \%$ and lower short time sick leave in office buildings by 35\% (Feige , et al., 2013).

\section{b. Thermal comfort}

Temperature has a great influence on occupants' performance, small temperature change of few degrees within range from $18^{\circ} \mathrm{C}-30^{\circ} \mathrm{C}$ can affect performance of typing, factory works and many cognitive tasks. Complex and creative mental work need optimum thermal conditions while slightly lower temperatures can enhance mental performance of different kinds of work and may increase arousal. (Harris \& Moore, 2009)

Laboratory studies came with these results through simulating office environments:

- Applying a personal temperature control over about $\pm 3^{\circ} \mathrm{C}$ can increase performance by $7 \%$ for typical office tasks, increase skilled manual performance by $3 \%$, and enhance logical thinking by $2.7 \%$ (Feige , et al., 2013).

- Adjusting temperature concurrently with ventilation rate and air quality results in less SBS symptoms (Huang, et al., 2012).

- Adjusting the temperature out of the range of $21-25^{\circ} \mathrm{C}$ was found to deteriorate performance by an average of $2 \%$ per $1{ }^{\circ} \mathrm{C}$ rise or fall, when reaching temperature of $30^{\circ} \mathrm{C}$, occupant performance is about only $91.1 \%$ of the maximum. (Harris \& Moore, 2009)

\section{c. Visual comfort}

Glare phenomenon is considered top of the most daylighting related issues reported by office occupants to cause discomfort (Isoardi, 2009) \& (Hua, et al., 2011). improper lighting was found to cause eyestrain for $44 \%$ of the US office occupants. Eyestrain was ranked as the most prevalent health problem related to lighting

\footnotetext{
${ }^{1} \mathrm{~L} / \mathrm{s} /$ person: US unit of airflow employed in air-conditioning.
} 
conditions and proved to cause performance decrement (Hedge, et al., 2007). Preventing glare and improving visual comfort could affect work performance as following:

- Improved lighting quality can enhance performance by $13.2 \%$ for drafting engineers and decrease absenteeism by 15\% (Edwards \& Torcellini, 2002).

- Natural views of vegetation and water have been associated with enhanced morale, reduced eyestrain, reduced stress, improved mood, less fatigue, producing positive responses, holding attention and decreasing anxiety (Edwards \& Torcellini, 2002). It was also found that occupants with offices near windows -even if not operable- have less SBS symptoms and express more satisfaction with lighting conditions than those with further workspaces (Feige, et al., 2013).

- Proper daylit office buildings resulted in reduced absenteeism, decreased headache and SAD, financial savings and increased productivity (Edwards \& Torcellini, 2002).

\section{d. Acoustics}

Office acoustics is considered one of the most tangible aspects of IEQ, satisfaction with noise can define the acoustical satisfaction state (Freihoefer, et al., 2015). Noise could probably affect human performance as following:

- $\quad$ Noise might interfere with work capability, decrease performance, and cause annoyance and interruption for occupants especially when the performed tasks involve creativity (Roelofsen, 2008).

- $\quad$ Noise could result in short-time memory loss, increase working pressure and depression, and later may cause tiredness (Roelofsen, 2008).

- Noise was found to raise stress hormone levels - comparing medical test results of 2 groups of occupants- and decreases motivation (Ermann, 2015).

\section{Indoor Environmental Quality Assessment Methods}

To evaluate a building, the actual situation of its performance should be compared with the initial designed intentions. Post Occupancy evaluation (POE) is a widely recognized approach to address the gap between intended design and actual performance. Building evaluation does not limit to its environmental performance, extended scope of evaluation includes social, economic, and cultural impact of the building. Post Occupancy evaluation (POE) helps assessing user satisfaction and performance in addition to building user productivity, atmosphere, identity and community (Hay, et al., 2017).

Post Occupancy evaluation (POE) can inform building operators about areas needing improvement, provide feedback to building designers and operators about installed design features and operating strategies which results in better next building designs being able to meet the needs of clients and users, explains how the 
user behavior can impact the performance of the building and how to improve this performance by making users aware of the efficient use, (Zagreus, et al., 2004) and (Hay, et al., 2017).

Building assessment programs have aroused to evaluate and compare the environmental performance of green buildings worldwide creating a fair competition between them based on integrated criteria of assessment. However Indoor environment quality assessment has a significant role in determining the environmental performance of the building, it is considered one of several issues that building assessment programs include. Mostly, IEQ and human comfort related issues are evaluated by assessing the factors known to influence comfortable ranges of different IEQ aspects using quantitative measurements. This approach is considered so complex as not all factors related to and influencing human sensation and perception can be measured using quantitative measurements and therefore, leading to unreliable results (Fekrya, et al., 2014).

Although the link between indoor office environment and user performance clearly exists and many relevant studies are available to show this link by variant approaches, there are still methodological difficulties presented in the shortage of proper assessment means to evaluate issues related to human sensation and comfort. This leaves unanswered questions and research gaps in this area of research. Main reasons can be summarized in the limited amount of available data to apply a conclusive research and the insufficient scope of research objectives (Feige , et al., 2013).

Studying previous researches (Zagreus, et al., 2004) and (McCartney \& Humphreys, 2002) showed that there are two common approaches followed to evaluate IEQ and user performance represented in: Physical measurement method and Selfassessment questionnaires.

The first approach depends on physical measurements and behavior monitoring in the office workspace -whether in real office or in a simulated office environment under laboratory conditions- to evaluate both IEQ and user performance (McCartney \& Humphreys, 2002) and (Huang, et al., 2012). Main research issues related to this approach are: 1) using quantitative measurements to assess implementing human comfort despite being human comfort subjective and of qualitative nature which would reduce the accuracy and credibility of the results (Fekrya, et al., 2014), 2) Not paying enough attention to the social aspects of sustainability concerning user performance and environmental requirement and Focusing on environmental and economic related aspects (Feige , et al., 2013), 3) Focusing on a narrow range of IEQ aspect in most simulated office environment (Feige , et al., 2013), and 4) Findings carried out under laboratory conditions mainly tend to have less validity and to be less conclusive when practically implemented (Feige , et al., 2013).

Another approach to follow instead of the use of quantitative standards is the selfassessment questionnaire. In this approach, occupants are asked to evaluate their own perceived performance and their satisfaction with indoor environmental 
conditions then their reported information is simply collected and analyzed (McCartney \& Humphreys, 2002). As the building user himself is a valuable source of information about indoor environmental quality and how it could influence comfort and performance, Self-assessment questionnaires are considered a more helpful approach to evaluate IEQ avoiding the use of quantitative standards (Zagreus, et al., 2004).

\section{Self-assessment questionnaire}

For the purpose of this paper, the self-assessment questionnaire method would be used to evaluate the perceived importance of IEQ in office workspaces. In addition to building performance assessment, this method can be used to identify areas needing enhancement and provide feedback about newly used design features and operating strategies to building designers and operators (Zagreus, et al., 2004).

Two common types of self-assessment questionnaire are the paper questionnaire and the digital questionnaire. Survey designer should decide the proper type to use depending on the time, cost, population age, and the objectives of the survey. digital questionnaire offers lower cost and time of data collection and can be flexible and repetitive. Some limitations of using digital questionnaires are presented in the need to have electronic infrastructure, Familiarity with using the computer, less preference by older population (Zagreus, et al., 2004).

The reliability of this approach is that it is relevant to everyday office work and not task dependent. As the study uses the same scale for all occupants to vote, results are ready to be compared right after conducting the survey. (McCartney \& Humphreys, 2002). In contrast to physical measurement method, self-assessment questionnaires can deal with descriptive, qualitative and subjective characteristics and handle different variables related to human sensation and performance (Fekrya, et al., 2014). Although this method seems to overcome many issues found in the physical measurements method, some research issues related to this approach should be considered when deciding to use it (Feige , et al., 2013) and (Fekrya, et al., 2014): 1) In order to get reliable and credible results, minimum number of required subjects for conducting the questionnaire should be achieved, 2) Filling the form depends only on the individual's interest so, raising the response rate requires raising the environmental awareness about the benefits of sustainable buildings amongst the addressed community in the first place, 3) Studies performed in real life probably lead to more valid findings but in many cases amount of data sets is not sufficient, and 4) This method is not unbiased, objective measurement and therefore the conclusions are slightly tenuous.

\section{Surveyed population characteristics}

The data of this survey is comprised of responses from 118 occupants performing typical office tasks in Egypt collected using an online survey platform. The data collected measured two types of variables: objective and subjective. 
The objective variables included type of workspace, means of ventilation, having window, and proximity to windows. The subjective variables included self-reported evaluation of indoor environmental quality aspects and determining the aspect that have the highest effect on performance.

In the questions evaluating the importance of IEQ aspects, a five-point semantic deferential scale was used with values ranging from 1 to 5 and endpoints "less important" and "more important" as shown in (Figure 1).

\begin{tabular}{|l|lllll|l|}
\hline & 1 & 2 & 3 & 4 & 5 & \\
Less important & 0 & 0 & 0 & 0 & $\bigcirc$ & More important \\
\hline
\end{tabular}

Figure 1:Semantic deferential scale.

Workspace type varied between respondents, shared enclosed offices had the biggest portion of 31\%, open plan offices with no partition came in the second place $22 \%$ followed by individual enclosed offices 20\% (Figure 2). For the ventilation type, $59 \%$ of the workspaces had the option to switch between natural and mechanical ventilation, $28 \%$ used mechanical ventilation and only $13 \%$ depended completely on natural ventilation (Figure 3).

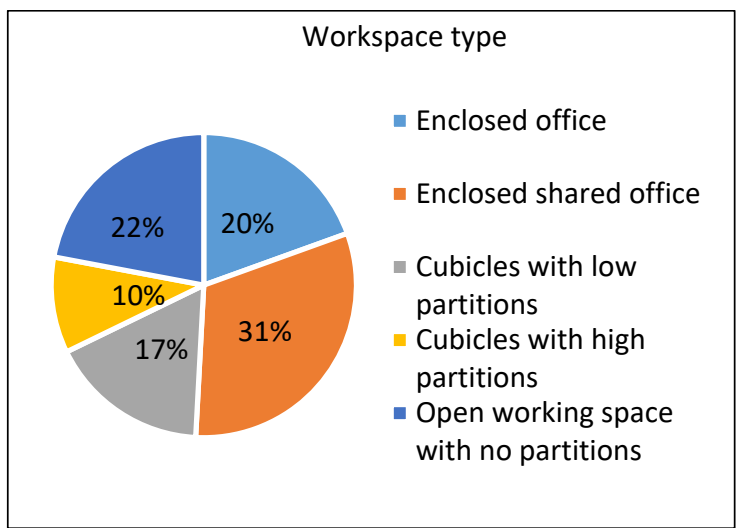

Figure 2:Distribution of occupants' workspace types.

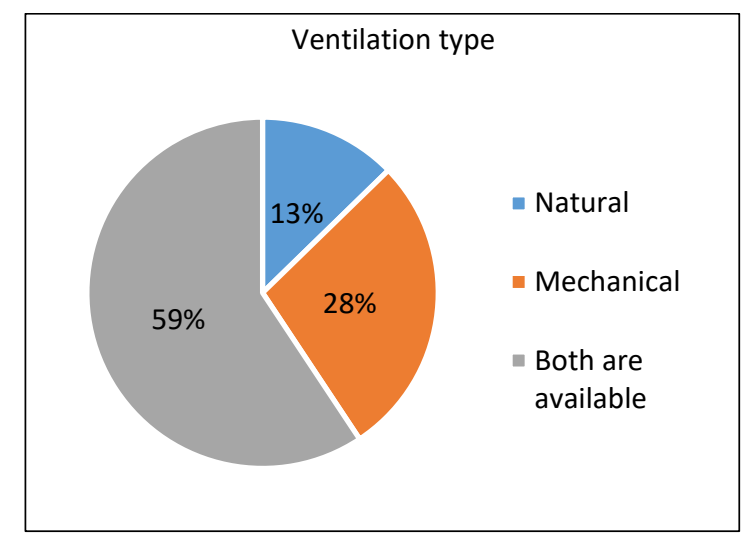

Figure 3: Distribution of the ventilation types across the buildings.

$14 \%$ of the surveyed workspaces did not have a window; However, the majority of workspaces where a window is available 65\%, it was located within the recommended distance of less than 4.5 meter (Figure 5). 


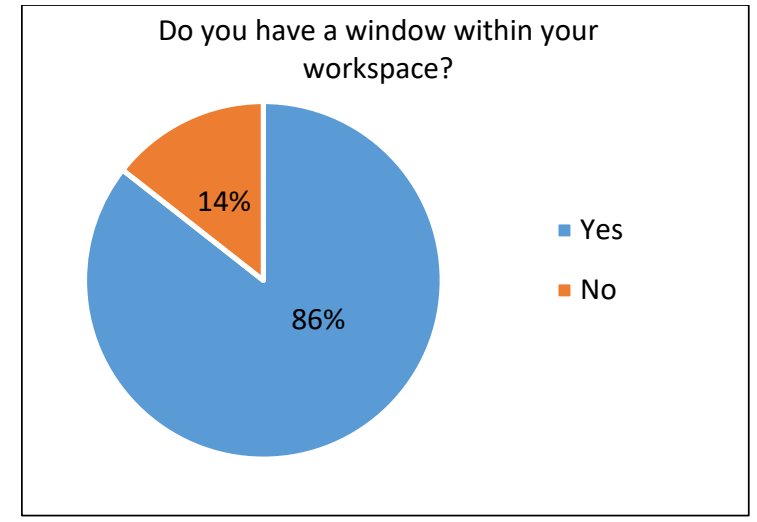

Figure 4:Distribution of the existence of a window within the workspace.

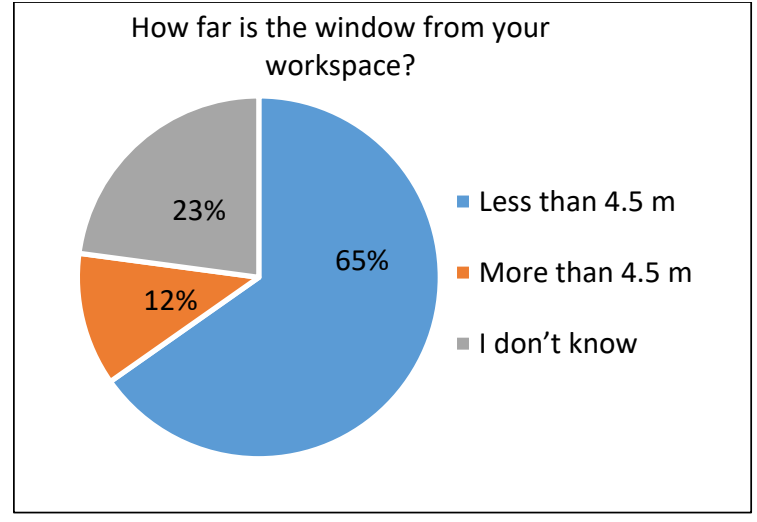

Figure 5:Distribution of proximity to nearest window.

\section{Results}

\section{Indoor air quality}

(Figure 6) shows how the respondents evaluated the importance of indoor air quality including air cleanliness, odors, stuffy air, and dust based on the effect of this factor over their work performance. $69.5 \%$ of the respondents rated this factor to have score 5 on the linear scale and only $8.5 \%$ of the sample reported neutral score.

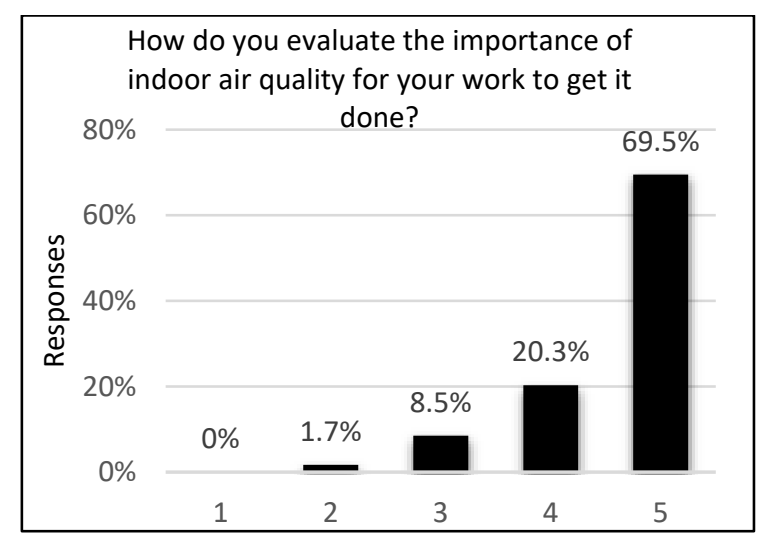

Figure 6: Occupants' evaluation of indoor air quality.

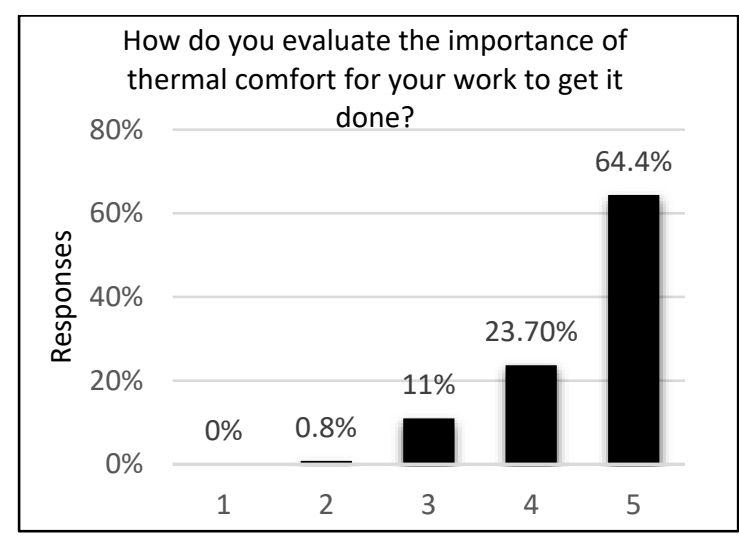

Figure 7:Occupants' evaluation of thermal comfort.

\section{Thermal comfort}

(Figure 7) shows how the respondents evaluated the importance of thermal comfort including temperature, humidity, and air speed based on the effect this factor has over their work performance. $64.4 \%$ of the respondents rated this factor to have score 5 on the linear scale and only $11 \%$ of the sample reported neutral score.

\section{Visual comfort}

(Figure 8) shows how the respondents evaluated the importance of visual comfort including lighting level, glare, reflections, and contrast based on the effect this factor has over their work performance. $70.3 \%$ of the respondents rated visual comfort to have score 5 on the linear scale which is considered the highest percentage of all factors and only $8.5 \%$ of the sample reported neutral score. 


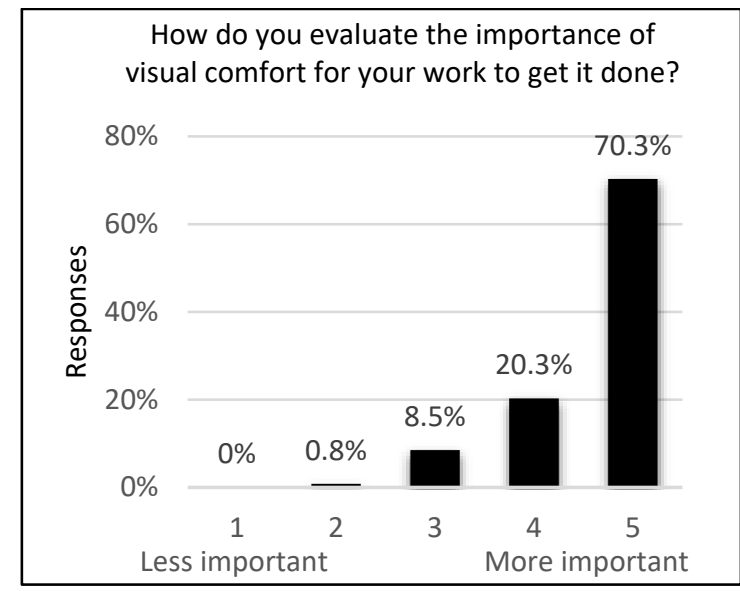

Figure 8: Occupants' evaluation of visual comfort.

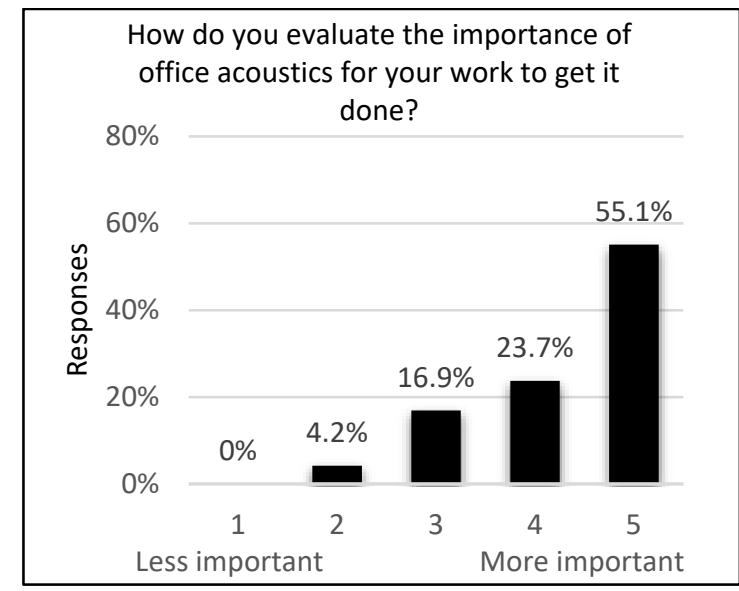

Figure 9: Occupants' evaluation of acoustics.

\section{Acoustics}

(Figure 9) shows how the respondents evaluated the importance of acoustics including noise and sound privacy based on the effect of this factor over their work performance. $55.1 \%$ of the respondents rated this factor to have score 5 on the linear scale which is considered the lowest percentage of all factors and a relatively high percentage $16.9 \%$ reported neutral score.

When the respondents were asked which IEQ factor mostly affects them during performing work tasks, almost one third of the sample $32.7 \%$ voted for thermal comfort followed by indoor air quality with $25.5 \%$ of the votes. Acoustics votes came in the third place with percentage of $21.9 \%$ and the least voted factor was the visual comfort with only $19.9 \%$ of the votes as shown in figure (Figure 10).

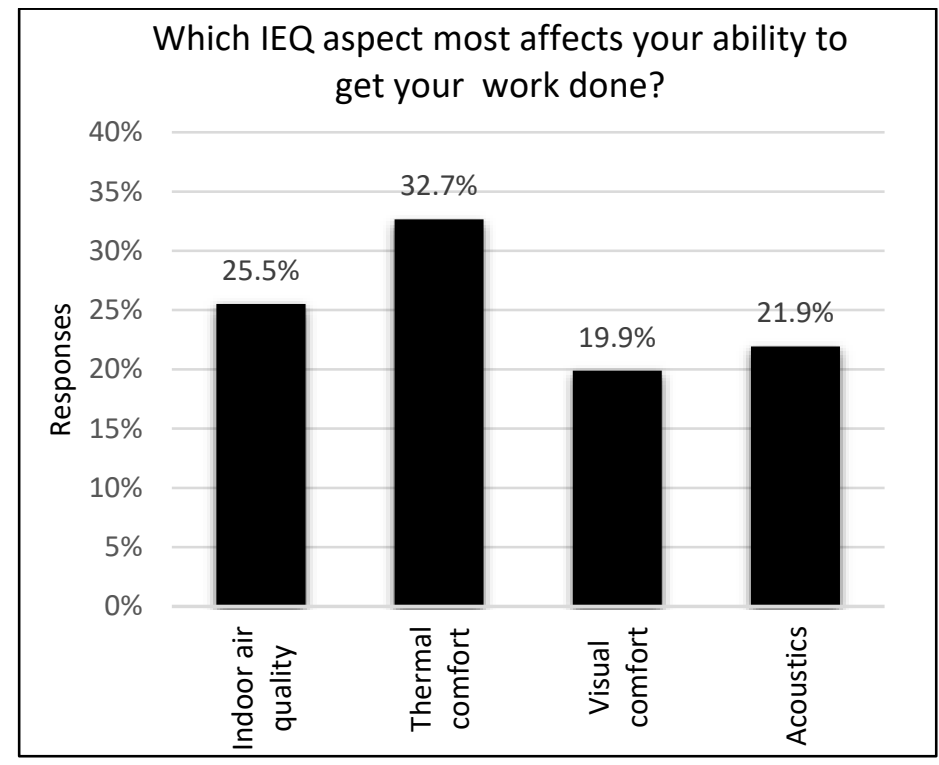

Figure 10:Distribution of the occupants' votes for the most affecting IEQ factor. 
By asking respondents about causes of dissatisfaction they experience within the workspace as shown in (Figure 11); Lack of outdoor views 15.3\%, Lack of natural ventilation $13.9 \%$, and Insufficient working area $12.5 \%$ came on top of the reported problems. Poor ventilation was also reported as a major problem $14 \%$ including complains about low ventilation rates, insufficient cooling loads, nonuniform distribution of cooling diffusers, and remarkable difference between indoor and outdoor temperatures. Problems related to visual comfort got $36.1 \%$ of the overall dissatisfaction sources, these problems were presented in the lack of having a window, window area is too small, insufficient daylighting, poor lighting levels, glare on computer screens, and lack of outdoor natural views within the workspace.

By noticing the influence of the workspace characteristics on the reported problems, it was found that almost all of the respondents having no nearby window reported the lack of daylighting and not having a window as sources of discomfort. The layout of the working area also affected respondents complains, while the majority of occupants working in enclosed offices did not report problems about ventilation, visual comfort or acoustics, $25 \%$ of them reported insufficient working area and inconvenient room layout as sources of discomfort.

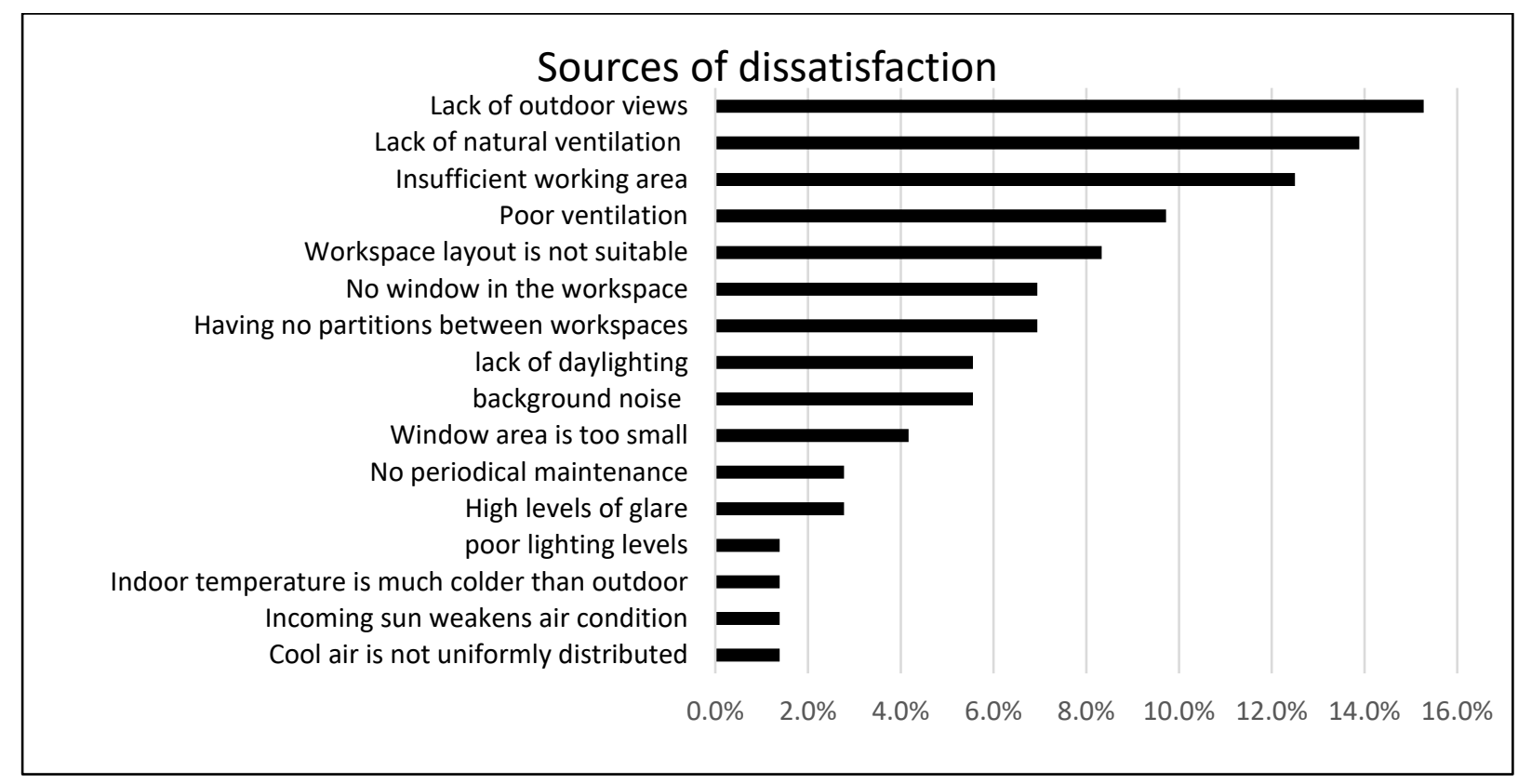

Figure 11: Sources of dissatisfaction.

\section{Discussion and conclusion}

The findings of this study show that thermal comfort followed by air quality are at the top of the IEQ factors affecting users' performance from their own point of view; However, the current situation shows that the majority of the reported issues causing user dissatisfaction in the office environment are relevant to visual comfort and views factor. It could be concluded that even when visual comfort was voted for as the least important IEQ factor, all of the four factors has a significant impact over 
the user performance and every deficiency in any factor might cause discomfort and consequently performance deterioration.

The results of this initial survey influence the main research in some points: 1) More attention would be given to the questions relevant to thermal comfort and air quality in the questionnaire supposed to evaluate IEQ in green buildings, 2) Avoiding openended questions when designing the following questionnaire and using multiple choice questions instead would noticeably raise the response rate.

Post occupancy evaluation approach applied using self-assessment questionnaire was found to be a proper approach to provide a feedback for building designers and operators about the building performance and whether it had met its intended environmental, economic, and social goals.

Proving that IEQ has a noticeable impact on office building users' performance would provide an interesting research subject to perform the same evaluation method for buildings of different nature such as: healthcare buildings, education buildings, and commercial buildings. One of the factors influencing the findings of this study is the location where it was performed, applying this survey in different locations might lead to significantly different findings including the evaluation of IEQ factors by building users and the reported issues.

\section{References}

- Edwards, L. \& Torcellini, P., 2002. A Literature Review of the Effects of Natural Light on Building Occupants, s.l.: National Renewable Energy Laboratory.

- Ermann, M., 2015. Architectural Acoustics Illustrated. s.l.:John Wiley \& Sons, Inc..

- Feige , A., Wallbaum , H., Janser , M. \& Windlinger , L., 2013. Impact of sustainable office buildings on occupant's comfort and productivity. Journal of Corporate Real Estate, 15(1), pp. 7-34.

- Fekrya, A. A., El Zafaranyb, A. M. \& Shamseldin, A. K., 2014. Develop an environmental assessment technique for human comfort requirements in buildings. HBRC Journal, 10(1), pp. 1-9.

- Freihoefer, K. et al., 2015. Occupants’ satisfaction with, and physical readings of, thermal, acoustic, and lighting conditions of sustainable office workspaces. Indoor and Built Environment, Volume 24, pp. 457-472.

- Harris, R. G. \& Moore, D. P., 2009. Indoor Work and Living Environments. New York: Nova Science Publishers.

- Hay, R. et al., 2017. Building Knowledge: Pathways to Post Occupancy Evaluation, RIBA: University of Reading.

- Hedge, A., William, R. S. \& Fraklin, D. B., 2007. Effects of lensed-indirect and parabolic lighting on the satisfaction, visual health, and productivity of office workers. Ergonomics, 38(2). 
- Hohwü, L. et al., 2013. Web-Based Versus Traditional Paper Questionnaires: A Mixed-Mode Survey With a Nordic Perspective. Journal of Medical Internet Research, 15(8).

- Huang, L., Zhu, Y., Ouyang, Q. \& Cao, B., 2012. A study on the effects of thermal, luminous, and acoustic environments on indoor environmental comfort in offices. Building and Environment, Volume 49, pp. 304-309.

- Hua, Y., Oswald, A. \& Yang, X., 2011. Effectiveness of daylighting design and occupant visual satisfaction in a LEED Gold laboratory building. Building and Environment, Volume 46, pp. 54-64.

- Isoardi, G., 2009. The Design and Testing of a Daylighting Device: Optimising the energy and optical performance of Australian commercial buildings. s.l.:Queensland University of Technology.

- McCartney, K. \& Humphreys, M., 2002. THERMAL COMFORT AND PRODUCTIVITY. Indoor Air, pp. 822-827.

- Roelofsen, P., 2008. Performance loss in open-plan offices due to noise by speech. Journal of Facilities Management, 6(3), pp. 202-211.

- Zagreus, L., Huizenga, C., Arens, E. \& Lehrer, D., 2004. Listening to the occupants: a Web-based indoor environmental quality survey. INDOOR AIR, Volume 14, pp. 65-74. 